\title{
O PROJETO FOSFATO TRÊS ESTRADAS NO ESTEIO DOS CONFLITOS AMBIENTAIS NO PAMPA GAÚCHO
}

\author{
Sérgio Botton Barcellos ${ }^{1}$ \\ https://orcid.org/0000-0002-6935-4398 \\ Camila Dalagnese Prates ${ }^{2}$ \\ https://orcid.org/0000-0003-0317-7074 \\ Júlio Picon $\mathrm{Alt}^{3}$ \\ https://orcid.org/0000-0002-1045-6859
}

\section{RESUMO}

A partir deste artigo, o objetivo é analisar como se configuram os conflitos ambientais na tentativa de instalação da mineração de derivados de fosfato, em Lavras do Sul, no estado do Rio Grande do Sul (RS). O marco teórico que ampara o trabalho é constituído pela lente analítica de processo histórico de longa duração e configurações sociais, em Norbert Elias; neoextrativismo, em Eduardo Gudynas; conflitos ambientais a partir de Henri Acselrad; e Isabelle Stengers para amparar a discussão sobre os papéis desempenhados pela ciência e pela política nesses contextos. Nesta análise, serão levadas em consideração as dimensões históricas, o contexto atual da mineração nessa região, as disputas e conflitos ambientais acerca da possível instalação desse empreendimento. A metodologia é qualitativa, a partir de observação participante, análise documental e de depoimentos públicos dos atores sociais como a empresa mineradora e interlocutores (as) na comunidade estudada. Compreende-se que os conflitos ambientais entre atores "contrários" e "a favor" da instalação deste empreendimento minerário no RS estimulam processos sociais distintos. Conclui-se que há um processo de avanço de fronteiras de exploração ambiental e territorialização desses grupos no bioma Pampa, pelo acúmulo de capital econômico financeiro, por meio da extração de bens naturais, como minérios, e atuação de grupos transnacionais com apoio de grupos nacionais e locais.

Palavras-chave: Bioma Pampa, Rio Grande do Sul, Conflitos Ambientais, Mineração, Fosfato.

\section{THE PROJETO FOSFATO TRÊS ESTRADAS IN THE STAY OF ENVIRONMENTAL CONFLICTS IN PAMPA GAÚCHO}

\begin{abstract}
From this article, the objective is to analyze how environmental conflicts are configured in the attempt to install phosphate derivatives mining in Lavras do Sul, in the state of Rio Grande do Sul (RS). The theoretical framework that supports the work is constituted by the analytical lens of the long-lasting historical process and social configurations in Norbert Elias, neo-extractivism in Eduardo Gudynas, environmental conflicts from Henri Acselrad and Isabelle Stengers to support the discussion about the roles played by science and by politics in those contexts. In this analysis, historical dimensions, the current mining context in the region, environmental disputes and conflicts over the possible installation of this enterprise will be taken into account. The methodology is qualitative based on participant observation, documentary analysis and public statements from

\footnotetext{
${ }^{1}$ Doutor em Ciências Sociais do Desenvolvimento, Sociedade e Agricultura CPDA-UFRRJ. Professor Adjunto do Departamento de Ciências Sociais da Universidade Federal da Paraíba. E-mail: sergiobbarcellos.ufpb@gmail.com.

${ }^{2}$ Doutora em Sociologia pela Universidade Federal do Rio Grande do Sul. Pós-doutoranda e professora colaboradora no Programa de Pós-Graduação em Sociologia da Universidade Federal de Pelotas. E-mail: camilapratescs@gmail.com.

${ }^{3}$ Graduação em Ciências Jurídicas e Sociais pela PUC/RS. Mestrando em Desenvolvimento Rural na Universidade Federal do Rio Grande do Sul. E-mail: julio.alt@gmail.com.
} 
social actors such as the mining company and interlocutors in the studied community. It is understood that the environmental conflicts between "opposing" and "in favor" of the installation of this mining enterprise in RS stimulate different social processes It is concluded that there is a process of advancing the frontiers of environmental exploration and territorialization of these groups in the Pampa biome, through the accumulation of financial economic capital, through the extraction of natural goods, such as minerals, and the performance of transnational groups with the support of national groups, and locations.

Keywords: Bioma Pampa, Rio Grande do Sul, Environmental conflicts, Mining, Phosphate.

\title{
EL PROYECTO DE FOSFATO TRES ESTRADAS EN EL SET DE CONFLICTOS AMBIENTALES EN PAMPA GAÚCHO
}

\begin{abstract}
RESUMEN
A partir de este artículo, el objetivo es analizar cómo se configuran los conflictos ambientales en un intento de instalar la minería de derivados de fosfato en Lavras do Sul, en el estado de Rio Grande do Sul (RS). El marco teórico que sustenta el trabajo está constituido por la lente analítica de un proceso histórico de larga duración y configuraciones sociales en Norbert Elias, el neoextractivismo en Eduardo Gudynas, los conflictos ambientales de Henri Acselrad e Isabelle Stengers para apoyar la discusión sobre las disputas en relación la ciencia y para la política en estos contextos. Este análisis tendrá lugar en dimensiones históricas, el contexto minero actual en esta región, disputas ambientales y conflictos por la posible instalación de esta empresa. La metodología es cualitativa basada en la observación participante, análisis de documentos y declaraciones públicas de actores sociales como la empresa minera e interlocutores en la comunidad estudiada. Se entiende que los conflictos ambientales entre "opositores" y "a favor" de la instalación de esta empresa minera en RS estimulan diferentes procesos sociales. Se concluye que existe un proceso de avance de las fronteras de exploración ambiental y territorialización de estos grupos en el bioma pampeano, mediante la acumulación de capital económico financiero, mediante la extracción de recursos naturales, como los minerales, y el desempeño de grupos transnacionales con ellos apoyo de grupos nacionales y locales.
\end{abstract}

Palabras clave: Bioma Pampa, Río Grande do Sul, Conflictos ambientales, Minería, Fosfato.

\section{INTRODUÇÃO}

Atualmente, estima-se que haja cerca de 30 mil empreendimentos de mineração no Brasil. A Agência Nacional de Mineração (ANM) justifica o aumento desses empreendimentos devido ao potencial geológico brasileiro não explorado, como pode ser visto pelas estimativas do Plano Nacional de Mineração 2030, em que é forte o estímulo à atividade de mineração. Esse direcionamento para a expansão dos processos minerários tem gerado conflitos ambientais e potenciais riscos ambientais motivados pelos empreendimentos de mineração e a suas formas de territorialização que se destacam no Brasil. De acordo com Gonçalves, Milanez e Wanderley (2018), a partir desses projetos extrativos, está se colocando uma parte significativa da matriz produtiva do país orientada para a exportação de minérios e a expansão da fronteira mineral no Brasil. 
No contexto do estado do Rio Grande do Sul, há a tentativa de construir quatro grandes ${ }^{4}$ empreendimentos minerários, dois deles, no bioma Pampa gaúcho: os projetos Caçapava do Sul e Fosfato Três Estradas. Eles se apresentam como a mais nova promessa de "desenvolvimento econômico" e de geração de "emprego", com a proposta de "dinamizar" uma matriz econômica historicamente de base pastoril. Ressalta-se que no bioma Pampa, no extremo-sul do Brasil, a sua biodiversidade está sendo substituída por silvicultura e monoculturas de arroz e soja, bem como tem atraído o interesse crescente de empresas mineradoras e pequenas centrais hidroelétricas. De acordo com IBGE (2020), também se destaca que, nesse bioma, em sua porção no RS, foi registrada a maior perda de área natural entre todos os biomas brasileiros nos últimos anos, com $16,8 \%$ do seu território.

Diante desse contexto, por meio deste artigo serão abordadas as disputas e conflitos que se configuram através do pedido e da tentativa de instalação de um deles, o Projeto Fosfato Três Estradas, situado no município de Lavras do Sul, localizado no distrito de Três Estradas e no município de Dom Pedrito, no distrito de Torquato Severo, RS. O projeto está gerando conflitos ambientais, antes mesmo de sua instalação, entre os povos e comunidades que vivem na região. A partir desse contexto, o objetiva-se analisar como se configuram os conflitos ambientais relativos à mineração de derivados de fosfato na região de Lavras do Sul.

Os atores que estão até o momento protagonizando essa disputa são: a empresa Águia Fertilizantes, comunidades locais ${ }^{5}$, pesquisadores (as) que buscam ampliar os debates e fomentar ações críticas junto ao Ministério Público Federal (MPF) da região e governo estadual. O empreendimento minerário em questão é de propriedade da Águia Fertilizantes S.A. (Fertilizer Eagle), empresa australiana que "tem como objetivo explorar minério de fosfato, produzindo assim 6,5 milhões de toneladas de concentrado de fosfato, com pureza de 30\% e 46 milhões de toneladas de calcário agrícola" (Golden Associates, 2017, p.13), a princípio, com duração de 50 anos de extração. Para o funcionamento do projeto, outras estruturas serão construídas, tais como: mina para extração a céu aberto, barragem de rejeito, barragem de água, pilhas estéril e planta de beneficiamento. É importante ressaltar que todo processo de licenciamento do projeto tem sido marcado por incongruências e acelerações que são acompanhadas em um inquérito aberto no MPF

\footnotetext{
${ }^{4}$ Os quatro projetos estão em análise de viabilidade ambiental no órgão ambiental do Estado, são eles: Projeto Mina Guaíba, para extração de carvão; Projeto Retiro, para extração de titânio; Projeto Caçapava do Sul para extração de cobre, chumbo, zinco e outros metais; Projeto Fosfato Três Estradas, para extração de fosfato.

${ }^{5}$ No contexto de pesquisa, quando se refere à comunidade, consideram-se: pequenos, médios e grandes produtores pecuários e agrícolas, quilombolas, indígenas e comunidades nos municípios. De acordo com o laudo pericial 938/2020/SPPEA- Ministério Público Federal, na página 5, consta no Decreto Federal, de 2007, em seu Artigo $3^{\circ}$ as seguintes definições: "I - Povos e Comunidades Tradicionais: grupos culturalmente diferenciados e que se reconhecem como tais, que possuem formas próprias de organização social, que ocupam e usam territórios e recursos naturais como condição para sua reprodução cultural, social, religiosa, ancestral e econômica, utilizando conhecimentos, inovações e práticas gerados e transmitidos pela tradição [...].
} 
que questiona e evidencia inconsistências técnicas no Estudo de Impacto Ambiental (EIA), na obtenção da Licença Prévia ${ }^{6}$, em 2019, e na solicitação da Licença de Instalação (LI), em 2021.

Para analisar o processo histórico e as relações interdependentes que configuram esse conflito ambiental e essas controvérsias ao longo do seu processo social, será acionado Elias (1994; 2000). Por conflitos ambientais, entende-se: “[...] aqueles envolvendo grupos sociais com modos diferenciados de apropriação, uso e significação do território [...]”, tendo origem “[...] quando pelo menos um dos grupos tem a continuidade das formas sociais de apropriação do meio que desenvolvem ameaçada por impactos indesejáveis - transmitidos pelo solo, água, ar ou sistemas vivos - decorrentes do exercício das práticas de outros grupos" (Acselrad, 2004, p. 26). A discussão do neoextrativismo será feita a partir de Gudynas (2016), o qual analisa os efeitos desse processo de exploração de elementos da natureza na atualidade, que geralmente são evidenciados nas localidades onde as mineradoras se instalam ${ }^{7}$. Em Stengers (2018), encontra-se amparo para discutir sobre a construção interessada, portanto, política do empreendimento que encontra na "Ciência" caminhos para concretizar seu objetivo.

A metodologia dessa pesquisa é qualitativa e tem aporte na coleta e análise dos dados por meio da observação participante, análise documental ${ }^{8}$, depoimentos públicos dos atores sociais com a empresa mineradora e interlocutores (as) na comunidade estudada. A pesquisa foi realizada entre os anos de 2017 a 2020, com a participação em reuniões públicas nas comunidades, no MPF e audiência pública ${ }^{9}$; análise de documentos técnicos da empresa, dentre eles o EIA-RIMA e documentos de análise de conjuntura econômica da matriz na Austrália, bem como postagens contidas no perfil público da empresa no Facebook; e depoimentos públicos coletados em jornais regionais e audiência pública.

$\mathrm{Na}$ primeira parte da discussão no artigo são contextualizados o bioma Pampa e o projeto minerário no município de Lavras do Sul. Na segunda, são analisados os conflitos ambientais associados à possibilidade de instalação do empreendimento e os atores sociais que têm interesses distintos sobre o uso e a geração de riqueza dos bens naturais, assim como as formas de viver neste território.

\footnotetext{
6 São três licenças: a prévia, que aprova a localização e a viabilidade ambiental do projeto; a de instalação, que permite ao empreendedor iniciar as obras; e a de operação, que permite o início das obras.

${ }^{7}$ Gudynas (2016) discute que há uma tendência atual ao aumento do volume e da intensidade da extração mineral que ele denomina como quarta geração de extrativismo. Nesse ciclo, a mão de obra utilizada geralmente é bastante especializada e qualificada, com pouca criação de postos de trabalho.

${ }^{8}$ A partir da análise técnica do EIA-RIMA, que está contida em diversos documentos técnicos que constam no Inquérito 1.29.001.000136/2017-92 (MPF Bagé).

9 Única audiência pública realizada no ginásio municipal de Lavras do Sul - RS, no mês de março de 2019, para consulta da comunidade local sobre a instalação do empreendimento.
} 


\section{O BIOMA PAMPA NO CONTEXTO DOS CONFLITOS AMBIENTAIS E DE LAVRAS DO SUL - RS}

O Pampa é composto principalmente por vegetação campestre e abrange o Uruguai, Brasil e Argentina, em uma área de aproximadamente $750 \mathrm{mil} \mathrm{km}^{2}$. No Brasil, esse bioma foi delimitado pelo Instituto Brasileiro de Geografia e Estatística (IBGE), apenas em 2004, junto com os demais biomas brasileiros. Também indicado como Campo Sulino, o mesmo representa $63 \%$ da área do $\mathrm{RS}$, com quase $180 \mathrm{mil} \mathrm{km}^{2}$, e abriga parcialmente o Aquífero Guarani. Apesar de uma aparente homogeneidade da vegetação de campos nativos, apresenta uma vasta biodiversidade entre serras, planícies e coxilhas, com gramíneas, formações arbustivas, banhados, capões de matas, butiazais, entre outros (MMA, 2017).

No Pampa, há duas bacias hidrográficas (Costeira do Sul e Rio da Prata) que são essenciais para a composição do Pampa gaúcho. Uma delas é a Bacia Hidrográfica do Rio Santa Maria, que possui uma área de 15.609,11 km², abarcando os municípios de Bagé, Dom Pedrito, Lavras do Sul, Rosário do Sul, Santana do Livramento e São Gabriel, com população estimada em 220.296 habitantes. O principal uso de água nesta bacia se destina ao abastecimento da população local, à dessedentação de animais e à irrigação. Déficits hídricos são verificados na bacia, principalmente nos meses de verão, quando ocorrem as demandas para orizicultura (SEMA, 2017). A outra é Bacia Hidrográfica do Rio Camaquã, pertence à Região Hidrográfica das Bacias Litorâneas e situada na porção central do RS, abrangendo uma área com $21.657 \mathrm{~km}^{2}$, com uma extensão aproximada de 430 $\mathrm{km}$, sendo que, ao longo da extensão do rio, há, total ou parcialmente, 28 municípios. É importante trazer as informações deste rio porque, de acordo com o comitê de gerenciamento da bacia hidrográfica do Rio Camaquã ${ }^{10}$, as nascentes do Camaquã se situam nas localidades de Torquato Severo, no município de Dom Pedrito, no município de Lavras do Sul. A estiagem é também observada na dinâmica desse rio na estação do verão e, ultimamente, tem se estendido até meados de maio ao longo dos últimos anos.

No Pampa, de acordo com o Ministério do Meio Ambiente (MMA), em 2017, estima-se que existam cerca de 500 espécies de aves, 100 de mamíferos e 3.000 espécies de plantas, com diversas espécies endêmicas de fauna e flora, nem todas descritas ainda ${ }^{11}$. Esse bioma é composto por uma diversidade, não só de ambientes, mas de culturas e sociabilidades que foram constituídas ao longo de muitas gerações no e com o Pampa, o que gera diferentes formas de coconstruí-lo, e relações de interdependência política, econômica e com o ambiente.

\footnotetext{
10 Ver essas e mais informações na página do Comitê: http://www.comitecamaqua.com/index.php/a-baciahidrografica/caracterizacao-geral

11 Tal biodiversidade de espécies de flora pode ser observada na consideração de que um metro quadrado de campo nativo pode conter mais de 50 espécies diferentes de plantas, tornando essas pastagens naturais adequadas ao pastoreio.
} 
Para entender a complexidade ambiental e social do Pampa, ampara-se na análise de Elias (2006), que entende os processos sociais como construções flexíveis, mutáveis e que se configuram por meio do desenvolvimento e transformações ocorridas ao longo dos anos, e de acordo com a figuração formada a partir das relações de interdependência que os indivíduos estabelecem entre si e em sociedade. Com isso, para compreender a possível dimensão dos danos causados por um empreendimento minerário e seus conflitos ambientais, é preciso levar em conta como se configuram os processos sociais, culturais e ambientais para os diferentes povos e comunidades que vivem no Pampa.

Historicamente, a pecuária extensiva sobre os campos nativos tem sido uma importante atividade econômica da região, desenvolvida não somente em grandes estâncias, mas principalmente em pequenas e médias propriedades. Os produtores rurais e pecuaristas familiares, grupos sociais que compõe os produtores de gado e ovinos, também configuraram sua identidade no contexto histórico de ocupação do Pampa, a partir de três principais características: processos de sucessão rural por fracionamento de terras das grandes estâncias; compra de terras por agricultores familiares que migraram de regiões de colonização; e a compra da terra pelos trabalhadores das estâncias (Fernandes; Araújo, 2016).

Vivendo em pequenas propriedades, os pecuaristas familiares ${ }^{12}$ têm como atividade principal a criação de animais bovinos, ovinos e caprinos, manejando tais rebanhos com mão de obra familiar. Além disso, cultivam cereais, tais como o milho, que são destinados tanto à alimentação humana, quanto dos outros animais, e o feijão. Na região do Alto Camaquã, alguns pecuaristas familiares estão organizados em associações de fomento e estímulo à produção, bem como em defesa dos seus interesses ambientais, culturais e econômicos (Barcellos, Vaz e Pinheiro, 2018). No Pampa, também há Comunidades Quilombolas, Povos Indígenas, Benzedeiras e Benzedores, Povo de Terreiro/ Povos Tradicionais de Matriz Africana, Pecuaristas familiares, Povo Pomerano, Pescadoras e Pescadores Artesanais, Ribeirinhas e Ribeirinhos, além do Povo Cigano que utiliza a região como rota de passagem.

O bioma também é configurado por grupos com relações de ênfase econômico-financeiras, visando o mercado exportador, e que, em suas ações, promovem os modelos de desenvolvimento que estão ocasionando transformações nestas paisagens e biodiversidade (Mazurana et al., 2016). A expansão da soja e a silvicultura estão associadas ao desenvolvimento e geração de renda por meio da expansão dessas atividades e também com a perda da biodiversidade e dos recursos naturais do Pampa. Neske (2014) analisa que, dentre as formas de ocupação econômica no Pampa, já passaram

\footnotetext{
${ }^{12}$ Desse modo, atualmente, por exemplo, a lida campeira, por exemplo, é uma dessas distintas formas de construir a vida no pampa. Contudo, ela ganha maior destaque institucional, na última década, quando passa a ter mapeado seu saber/ fazer como parte de um conjunto mais amplo de viver e alterar o ambiente. Nesse sentido, o Instituto do Patrimônio Histórico e Artístico Nacional (IPHAN) também incentiva projetos que tenham objetivo de inventariar os saberes e modos de fazer pecuários na Pampa (Rieth et al., 2020).
} 
pela atividade latifundiária agropastoril, e, posteriormente, pela expansão do agronegócio, incluindo a silvicultura. Todos esses empreendimentos, com os seus modelos de desenvolvimento propostos, estão gerando a perda de biodiversidade e o comprometimento do bioma Pampa, que já é o segundo mais alterado do Brasil, com apenas 36\% de cobertura original e já acomete formas de vida de diversas comunidades (MMA, 2017).

Sob essa perspectiva, a partir dos anos 2000, na metade sul do RS, a região passou a ser alvo de novas investidas de grandes empreendimentos, na busca de um almejado crescimento econômico de uma área considerada a parte menos "desenvolvida" do Estado. Assim, os cultivos de soja e milho transgênicos ${ }^{13}$ se propagaram sobre os campos nativos, ocasionando a multiplicação de espécies exóticas, tais como o capim-anoni. Há também o investimento na plantação de lavouras de silvicultura (especialmente com eucaliptos, pinus e acácia negra). Em relação aos cultivos agropecuários, muitas destas atividades se pautam na agricultura com base na monocultura (com uso intenso de insumos e tecnologias externas), especialmente a sojicultura, sendo estimuladas por sucessivos governos de estado e municipais, bem como por empresas ligadas ao agronegócio que expandiram sua fronteira agrícola na metade sul do RS.

$\mathrm{Na}$ última década, acompanha-se o avanço de projetos de mineração que incorporam as características já mencionadas das "políticas de desenvolvimento" para o Alto Camaquã. Tem sido observado nessa região, identificada geologicamente como Escudo Sul-Riograndense ${ }^{14}$, o interesse pelas reservas de metal precioso, desde as jazidas já conhecidas e os antigos garimpos, até novas áreas com potencial, em municípios como Caçapava do Sul, Encruzilhada do Sul, Lavras do Sul, Santana da Boa Vista, São Sepé e Pinheiro Machado. Nestes municípios, algumas áreas vêm sendo alvo, desde 2008, de um intenso trabalho de pesquisa geológica para detectar pontos promissores, ampliar as reservas existentes e viabilizar projetos de extração mineral. Exemplo disso são os dados da Agência Nacional de Mineração (ANM), nos quais consta que há um cadastro de cerca de 160 processos ativos de prospecção para busca de ouro, chumbo, cobre, prata e zinco na região do Bioma Pampa (Barcellos, Vaz e Pinheiro, 2018) ${ }^{15}$.

Sob essa perspectiva, a configuração desse conflito na região em relação à possibilidade de mineração de derivados de fosfato, por parte da Águia Resources, com apoio do governo do estado, também é relativa a outros conflitos pretéritos no bioma Pampa em relação à própria mineração, à silvicultura e à sojicultura. Isto é, os atuais conflitos ambientais são configurados por distintos

\footnotetext{
${ }^{13}$ Esses processos desencadeiam reconfigurações espaciais, novas dinâmicas sociais, ambientais e de convivência nos territórios a partir da influência da mineração na produção social do espaço, sua organização, planejamento e efeitos sobre as temporalidades e modos de vida dos sujeitos e seus lugares (Gudynas, 2016).

14 Conhecido também como Serra do Sudeste, é formado por uma área triangular que ocupa aproximadamente os municípios de Porto Alegre, Dom Pedrito e Jaguarão. Essa área está dividida pelo vale do rio Camaquã, uma ao norte, que é a Serra do Herval, e outra ao sul, que é a Serra dos Tapes.

${ }^{15}$ Destaca-se que, no geral, de acordo com a ANM, até o ano de 2019, o RS contava com 5.192 requerimentos de autorização de pesquisa mineral visando o subsolo gaúcho.
} 
modos de apropriação técnica, econômica, social e cultural na atualidade e no passado, a partir de uma distribuição desigual de capitais econômico, político e simbólico que tendem a definir o poder de ação e discursivo entre atores sociais no território (Zhouri; Laschefski, 2010; Acselrad, 2004).

Breve contexto histórico de Lavras do Sul

Um dos municípios que faz parte do Pampa é o de Lavras do Sul-RS ${ }^{16}$, que se originou de um acampamento mineiro nas margens do Rio Camaquã para exploração de ouro ao longo do leito no rio. Há registros históricos de exploração de ouro por portugueses e espanhóis ${ }^{17}$ e de que também ocorreram guerras guaraníticas quando o município era a freguesia de Santo Antônio das Lavras no século XVIII. Com o término da Guerra do Paraguai, a mineração teve um impulso com a instalação da companhia inglesa Gold Mining Company. O ouro era explorado nas aluviões, no arroio Camaquã das Lavras e seus afluentes e, só em 1845, a empresa The Rio Grande do Sul Gold Mining Company começou as explorações dos filões auríferos (Frizzo, 2002).

$\mathrm{Na}$ segunda metade do século XIX e primeira do século XX, diferentes empresas estrangeiras estiveram minerando ouro no município, como a Companhia Lape, Tahourne Companhia Belga e Gold Field Mining Company. Na época, as atividades não perduraram devido às quedas dos teores do mineral e à pouca tecnologia disponível para explorações minerais mais amplas e aprofundadas (Frizzo, 2002). Com relação ao cobre, algumas ocorrências são conhecidas desde o início do século XIX, próxima à época do início da exploração do ouro no município. Em 1873, a Companhia das Minas de Ouro e Cobre do Sul do Brasil foi autorizada a lavrar jazidas de ouro e cobre onde atualmente se situam os municípios de Lavras do Sul e Caçapava do Sul. Registra-se que, em 1888, os alemães Maximiliano Saenger, Ricardo Saenger e Emílio Kleinod iniciaram a prospecção da jazida de cobre Camaquã (Frizzo, 2002). Em maio de 1882, a localidade passou à categoria de Vila, com o nome de Santo Antônio das Lavras, formada por territórios dos municípios de Caçapava do Sul e Bagé. Em 1938, passou a ser o município de Lavras do Sul.

Nos anos 1970, com tecnologias mais avançadas, a Companhia Riograndense de Mineração (CRM) reiniciou os trabalhos na área aurífera do município. A iniciativa da CRM e a revalorização do ouro, em 1980, geraram novos interesses de exploração desse minério na região (Frizzo, 2002). Entre as décadas de 1970-80, a Companhia Brasileira de Cobre (CBC) realizou trabalhos de prospecção em solo, rocha e sedimento de corrente, principalmente, nas minas Cerrito e Bloco do Butiá. Atuaram em Lavras do Sul, nesse período, além da CRM, várias empresas privadas, entre

\footnotetext{
${ }^{16}$ Atualmente, a população estimada pela PNAD (2019) é de 7.480 pessoas em Lavras do Sul.

${ }^{17}$ As disputas pelas terras conquistadas por Portugal e Espanha originaram tratados de limites como os de Madri e de Santo Ildefonso que tiveram suas linhas determinadas em documentos e posteriormente demarcadas, e as linhas dos dois tratados unem-se justamente sobre o território do município de Lavras do Sul, formando um vértice histórico (Frizzo, 2002).
} 
elas a Companhia de Mineração e Participações (CMP), na década de 1980, e a CBC, a Placer Dome do Brasil e a Seahawk, na década de 1990 (Frizzo, 2002). Após esse período descrito, registra-se que, a partir de 2000, empresas multinacionais voltaram a ter interesse na região (Bongiolo, 2006).

No fim de 2010, a empresa australiana Águia Resources adquiriu os projetos de fosfato Joca Tavares e Três Estradas, que eram da Companhia Brasileira de Cobre (CBC). O projeto inicialmente foi chamado Fosfato Rio Grande, e a empresa de referência era Águia Metais. Em 2014, ocorreu definitivamente a chegada da empresa no município de Lavras do Sul. Especialmente com a criação do site do projeto, em 2017, os nomes/ marcas do Projeto Fosfato Três Estradas e da Águia Fertilizantes (criada em 2012) foram mais amplamente divulgados. O grupo Águia Resources ${ }^{18}$ segue com intenção de implementar, além de projetos de fosfato, outros projetos como cobre e outros minerais na região (Rio Grande Projects) ${ }^{19}$.

Destaca-se que os recursos naturais, como solo e a água da região, foram utilizados para descarte de rejeitos da mineração. Casos de poluição ambiental foram relatados na região pela exploração do ouro que era feita por meio da amalgamação com mercúrio, gerando diversas áreas com passivos ambientais (Grazia; Pestana, 2005). Estudos indicam que até o ano de 1981, o estéril e o rejeito da $\mathrm{CBC}$ eram depositados na área de várzea da Microbacia Hidrográfica do Arroio João Dias (MBHAJD), e em outros locais impróprios. ${ }^{20}$ Atualmente, de acordo com Bruch (2016), constata-se que o referido arroio gerou entre a represa construída para mineração e a foz, no Rio Camaquã, o acentuamento do nível de assoreamento do leito, causado, provavelmente, pela construção da barragem de rejeitos e deposição dos mesmos (Bruch et al., 2006). O histórico da mineração em Lavras tem sido acompanhado pela produção de passivos ambientais que não são contabilizados nos cálculos das supostas promessas de desenvolvimento econômico.

\section{O PROJETO FOSFATO TRÊS ESTRADAS E OS CONFLITOS AMBIENTAIS EM MEIO AO LICENCIAMENTO AMBIENTAL}

Percebe-se que, para compreender as controvérsias políticas e as posições dos diferentes atores sobre a construção, ou não, deste projeto, é preciso levar em consideração a diversidade cultural, político-ideológica e discursiva que envolve os conflitos ambientais. Projetos, como o caso da Águia Resources, reconfiguram uma dinâmica regional, impactando espaços físicos, ecossistemas terrestres e aquáticos, e, principalmente, uma rede de relações sociais que se

\footnotetext{
${ }^{18}$ Informações extraídas do site:

https://www.noticiasdemineracao.com/print article/noticiasdemineracao/news/1127441/aguia-resources?print=true .

${ }^{19}$ No site australiano da empresa, estão disponíveis apresentações corporativas para os acionistas, que detalham o interesse pelo cobre na região do Bioma Pampa. Entre Caçapava e Lavras, a empresa possui oito projetos de mineração de cobre em fase de pesquisa. Rancho Grande, Carlota, Andrade, Primavera, Passo Feio, Seival, Canhada e Lagoa Parada compõem o Projeto Rio Grande, de exploração de Cobre. Mais informações: https://aguiaresources.com.au/ .

${ }^{20}$ Ver mais informações em: http://verbetes.cetem.gov.br/verbetes/ExibeVerbete.aspx?verid=5
} 
configuram nesse território. Essas alterações terão um maior impacto na reconfiguração das relações sociais, conforme as relações estabelecidas por essas populações com o ambiente físico e o meio biótico local, ou seja, se suas estratégias de existência e trabalhos estiverem relacionadas ao meio, essa condição está ameaçada pela implementação deste empreendimento (Acselrad; Da Silva, 2011).

É importante ressaltar que os conflitos ambientais envolvem grupos sociais que se posicionam criticamente sobre o projeto. Assim, o processo do licenciamento é um espaço que propicia, além do mapeamento dos impactos, o acompanhamento de demandas que emergem ao longo da tentativa de construção do projeto e se elas são acolhidas ou não. Em 2016, o empreendedor contratou a consultoria Milcreek Mining Group, dos Estados Unidos, com o objetivo de otimizar o estudo de viabilidade econômica do projeto Três Estradas. A Golder \& Associates também foi contratada para produzir o EIA - RIMA do Projeto. No entanto, os referidos estudos contêm uma série de incompletudes e têm sido alvo de várias críticas de pesquisadores da região e de especialistas contratados pelo MPF, que ainda não foram explicados ou corrigidos no âmbito do licenciamento ambiental, conforme será visto.

Além da centralidade da empresa na construção dos dados e das versões sobre aquele ambiente, há também mais um fator que impulsiona a construção do projeto: a busca pela licença social para operar em Três Estradas. Ou seja, trata-se de uma estratégia não-formal de marketing que se ampara na contratação de uma empresa de publicidade para elaborar a comunicação social com o anúncio de promessas como benefícios tributários superestimados para o município e região, bem como um apelo de propaganda a símbolos da cultura popular e regional como forma de estimular um sentimento de pertença e de legitimação social da empresa com as comunidades em Lavras do Sul. No site do "Projeto Fosfato Três Estradas", por exemplo, há um link chamado "Gente de Lavras", no qual são mostradas pessoas da comunidade e apresentados relatos sobre a vida da população local. Além disso, na primeira reunião da empresa com a comunidade, em 2018, denominada "Conversas com a comunidade", as apresentações do projeto minerário incorporavam imagens relativas à cultura campeira e demais elementos da cultura gaúcha. Também se registra o patrocínio em festivais culturais, eventos recreativos e artistas locais durante os anos de 2017 e 2018.

Ao mesmo tempo, o governo do estado se manifesta favorável à instalação do empreendimento e isso ocorre por meio da flexibilização de instrumentos legislativos de regulamentação ambiental, como a Lei do Licenciamento, ZEE / Plano Estadual de Mineração Plano Energético do RS que reformulam normatizações para acelerar procedimentos estatais sobre o tema. Outros atores fortalecem a rede de apoiadores da mineração, como o governo municipal de Lavras do Sul, parte da comunidade que vive na porção urbana longe do local de instalação da 
mineradora e associações comunitárias locais. A alegação para a defesa da instalação perpassa pela opinião, construída por meio das investidas para conquista da licença social, de que ocorrerá geração de emprego, aumento da arrecadação de impostos e dinamização econômica na região. Desse modo, algumas comunidades e líderes políticos locais podem ser identificados defendendo a mineração como uma fonte de emprego e desenvolvimento local, reconhecendo até mesmo os danos ambientais que tais empreendimentos poderiam causar.

A configuração deste conflito ambiental ${ }^{21}$ que ocorreu pela divergência de versões e de interesses, está entre os grupos e associações que se manifestaram contra a instalação do Projeto Fosfato Três Estradas, a Associação de Desenvolvimento do Alto Camaquã (ADAC), Associação pela Grandeza das Palmas (AGRUPA), Fundação Luterana Diaconina (FLD), pelo Comitê dos Povos e Comunidades Tradicionais do Pampa, o Comitê de Combate à Meganimeração (CCMRS), bem como moradores locais da área rural do município, atores da sociedade civil, como grupos de estudos vinculados a universidades (UFPel, FURG, UFRGS), e grupos comunitários auto organizados. Diferentemente do primeiro grupo, esse conjunto de atores sociais resiste à instalação do empreendimento, a partir da: atuação sistemática em audiências públicas; denúncias e apresentação de contraestudos nos meios de comunicação e junto ao Ministério público da $3^{\mathrm{a}}$ região; produção de documentários; atuação em mídias digitais como o Facebook; organização de eventos para mostra da produção local; formação e ampliação de associações locais; e promoção de debates sobre a necessidade de fomento das cadeias produtivas locais, como ovinocultura, artesanato, fruticultura, apicultura, turismo rural, etc.

Além disso, esses grupos denunciam publicamente nas mídias digitais e manifestações públicas que a justificativa do empreendimento em se instalar na região não seria em prol de desenvolvimentos econômicos baseados nas potencialidades locais, sociais e ambientais, mas voltada aos interesses econômicos da empresa ${ }^{22}$ e do governo do estado com a alegação de aumento da arrecadação tributária, e para transformar o Estado em um polo de investimentos, conforme consta no documento "Mineração no RS: Diagnóstico setorial e Visão de futuro", elaborado em

\footnotetext{
${ }^{21}$ Esse conflito ambiental está notificado como conflito socioambiental de visibilidade internacional e está mapeado na plataforma EJAtlas. Essa plataforma faz parte do projeto Environmental Justice Organisations, Liabilities and Trade (EJOLT), do qual participam mais de 100 especialistas e pesquisadores de 23 universidades e organizações nãogovernamentais, de 18 países pelo mundo. O projeto é coordenado no Instituto de Ciência e Tecnologia Ambiental da Universidade Autônoma de Barcelona (UAB), na Espanha. O Mapa da Justiça Ambiental contém um atlas de mapas temáticos e regionais que abrangem os conflitos de distribuição ecológica em todo o mundo, baseando-se no conhecimento ativista e vinculando-os ao fluxo de comércio material entre outras variáveis, e fornecendo uma plataforma de comunicação entre EJOs e cientistas que trabalham em questões relacionadas. Mais informações disponíveis em: http://www.ejolt.org/.

${ }^{22} \mathrm{O}$ primeiro impacto ambiental gerado, mesmo antes da sua instalação e operação, pelo Projeto Fosfato Três Estradas, em Lavras do Sul - RS. No mês de abril de 2017, a empresa Rede Engenharia e Sondagem S/A, contratada pela empresa Águia Fertilizantes S/A, que realiza a prospeç̧ão da mineração, foi notificada pela Brigada Ambiental, por crime ambiental contra flora (Morais; Rosseto, 2019). Foi registrado o corte de aproximadamente 230 árvores e bombeamento de água de um curso hídrico sem autorização ou licença do órgão ambiental competente (NGO ${ }^{\circ}$ 2242371).
} 
2018. No embate técnico e científico, pesquisadores (as) locais atuam para construir estudos críticos baseados nos dados e nos resultados informados pela equipe do empreendedor, além de construir outros que mapeiam os efeitos, caso o empreendimento se instale, relativos à perda de biodiversidade, privações hídricas, alteração de paisagem, degradação estética e toda sorte de problemas sociais correlacionados.

Os eventos expostos pelos atores críticos estão alinhados com a declaração do Comitê dos Povos e Comunidades Tradicionais do Pampa que alerta para o "esquecimento" nos estudos de impacto de populações tradicionais na região:

[...] da presença de Povos e Comunidades Tradicionais, de assentamentos da reforma agrária e de comunidades urbanas e rurais da região, e daquelas que vivem ou dependem dos recursos hídricos ao longo das Bacias dos rios Santa Maria, Camaquã e Negro e ao longo dos rios a jusante, como o rio Ibicuí ${ }^{23}$.

Sob essa perspectiva, as organizações sociais contrárias à instalação do empreendimento declaram que o EIA- RIMA não considera, por exemplo, as diversas características socioculturais intrínsecas aos Povos e Comunidades Tradicionais da região, como as guardiãs e os guardiões das águas, do solo e do patrimônio genético, a manutenção de práticas culturais e espirituais próprias, o cultivo de sistemas de produção agrodiversos e culinária própria que objetivam a soberania e segurança alimentar.

Cabe destacar que, nesses casos, na Constituição Federal e o Decreto 6040/2007 (Política Nacional de Desenvolvimento Sustentável de Povos e Comunidades Tradicionais), bem como na Declaração Universal dos Direitos Humanos da ONU, no Pacto Internacional sobre Direitos Econômicos, Sociais e Culturais da ONU, no Pacto Internacional dos Direitos Civis e Políticos da ONU e na Convenção no 169/1989 da OIT (Organização Internacional do Trabalho), estão previstos o processo de consulta específica, livre, prévia e informada junto aos Povos e Comunidades Tradicionais. E, de acordo com denúncias das organizações e lideranças comunitárias locais, isso também está sendo mais um elemento que configura o conflito ambiental estudado na região.

Ressalta-se que o avanço da exploração de recursos minerais e as monoculturas de exportação geralmente causam fortes impactos territoriais, em muitos casos, em áreas remotas representam a chegada de contingentes de operários, técnicos e equipamentos, criando economias de enclave de base extrativista, com a promoção e defesa por parte dos governos municipais, estaduais e federal. Estes empreendimentos requerem redes de comunicação e estruturas de apoio, criando um conjunto de enclaves e suas conexões com os mercados financeiros e de commodities globais, tendencialmente causando tensões territoriais. Ou seja, percebe-se que a gestão territorial

${ }^{23}$ Entrevista disponível em: https://www.sul21.com.br/ultimas-noticias/geral/2020/08/laudo-reconhece-existencia-decomunidade-tradicional-e-comite-pede-anulacao-de-licenca-para-projeto-de-mineracao/ . Acessado em: 17 nov. 2020. 
do neoextrativismo está adaptada a estes empreendimentos e não aos arranjos produtivos e a diferentes formas de vida dos povos e comunidades em meio à biodiversidade dos ecossistemas locais (Gudynas, 2012).

O licenciamento ambiental como espaço de mediação dos conflitos ambientais?

Os primeiros estudos para o licenciamento do projeto ocorreram em 2011, sendo apresentado, à população, o EIA/RIMA, através de audiência pública, em 2019. Também em 2019 a empresa conquista a primeira licença ambiental, a Licença Prévia. De lá pra cá, a empresa tem que responder aos inúmeros questionamentos da sociedade civil, universidade, MPF e da FEPAM sobre as lacunas e subdimensionamentos dos impactos negativos e riscos ambientais, tanto no EIA, quanto nos estudos complementares apresentados pela empresa.

Em maio de 2020, a empresa solicita a alteração do projeto através do documento "Projeto Fosfato Três Estradas - Adaptações na Fase 1". De modo geral, o projeto inicial ganhou um incremento de 14 anos, passando a 64 anos de operação. As transformações sugeridas não dizem respeito ao projeto como um todo, ou seja, o projeto inicialmente licenciado segue com a mesma complexidade, no entanto, a empresa sugere particioná-lo em três fases. As alterações na fase I consistem em: diminuir a área de construção do empreendimento e a não construção da barragem de rejeitos. A Fase I do Projeto foi adaptada para a produção de Fosfato Natural de Aplicação Direta (DANF - Direct Application Natural Fertilizer), com a projeção de uma infraestrutura simplificada. Nessa fase, ela estende a vida útil da mina "de 4 para 18 anos, o que representa 14 anos adicionais de operação" (Águia, 2020, p. 3).

Com essa alteração temporal, a empresa alega que os impactos negativos da obra serão reduzidos pela diminuição na Área Diretamente Afetada (ADA) de aproximadamente "77,3\% em relação à ADA originalmente planejada para a Fase 1, abrangendo uma área de 93,2 hectares" (ÁGUIA, 2020, p.11). O posicionamento da FEPAM tem sido de aceitar em grande parte das modificações propostas “com vistas ao licenciamento da Fase I, considerando que as Fases II e III deverão ser objeto de licenciamento específico quando houver necessidade de impactar as áreas para construção das estruturas que ainda estão previstas" (FEPAM, 2020, p. 5). A Águia declarou em sua página no Facebook ${ }^{24}$ que:

O prazo estimado para implantação do Projeto Fosfato Três Estradas, após a liberação da licença ambiental, é de um ano. Com a obra concluída daremos início a um ciclo que irá durar 64 anos: 18 na primeira fase (onde o minério oxidado será beneficiado), 19 na segunda fase (quando o minério em rocha fresca será beneficiado e o calcário agrícola será produzido) e a terceira fase de 27 anos (quando haverá a secagem e venda do calcário agrícola).

\footnotetext{
${ }^{24}$ Disponível na página do Facebook do Projeto Fosfato no link: https://www.facebook.com/projetofosfato/ . Acessado em: 21 set. 2020.
} 
Entretanto, essas alterações foram alvo de denúncia ao Conselho Estadual de Direitos Humanos (2020), porque, conforme laudo pericial 938/2020, contratado pelo MPF, constata a existência da Comunidade Tradicional do pequeno Pecuarista Familiar (Prates et.al., 2020). As recentes alterações propostas pela empresa ampliam os impactos ambientais ao pecuarista familiar da região, ainda mais aos que antes estavam na Área Diretamente Afetada (ADA) e que agora estão na região considerada Área de Influência Direta (AID) (Prates et al., 2020, p.30).

Diante do exposto, percebe-se que o conflito ambiental extrapola o processo burocrático e revela associações mais complexas e problemas ambientais e sociais acumulados historicamente na região. No âmbito do licenciamento, o conflito ambiental é traduzido a partir da operação de categorias técnicas, como as de "impacto", para diagnosticar os efeitos considerados positivos e negativos do projeto, e como a de "atingido", que delimita os grupos sociais e os ambientes que irão sofrer impactos negativos pelo projeto (Vainer, 2008).

A controvérsia de termos técnicos e científicos faz parte da disputa da construção da realidade que contém critérios políticos de seleção (Stengers, 2018) e que se refere a vidas e outras formas de existir na localidade de Lavras do Sul e no próprio bioma Pampa ${ }^{25}$. Frente à centralidade da ciência na construção da viabilidade ambiental do projeto, considera-se que uma das formas de “democratizar" esse processo é desacelerando e resistindo ao modo como uma informação nos é apresentada e a imposição de outras formas de viver (Stengers, 2018). Em relação a isso, em declaração recente ao Jornal Minuano ${ }^{26}$, um morador da região reflete que

[...] está neste processo com a Águia desde 2011 e frisa que não quer ver sua propriedade ser desmanchada pela mineradora. "A barragem de resíduos vai ficar dentro da minha propriedade e o local é rico em nascentes que não serão preservadas", relata. O produtor salienta que a região é rica em sítios arqueológicos e mata nativa.

A notícia enuncia a inequação dos estudos à realidade e esse fato tem sido mapeado pelas tentativas de diálogo e de crítica que os grupos contrários manifestam ${ }^{27}$. No quadro, 1 é possível acompanhar movimentações de documentos que mapeiam as negociações realizadas entre a empresa Águia, a FEPAM, além da tentativa do Ministério Público Federal (MPF) em intervir no

\footnotetext{
${ }^{25}$ Há também a ideia do objeto técnico concreto construído através das epistemes locais que são os protocolos de consulta que podem ser entendidos aqui como documentos técnicos políticos localizados epistemologicamente (Oliveira; Losekann, 2015). Entretanto, para que se tenha esse direito reconhecido, é preciso que se reconheça a presença no território assediado pelo "desenvolvimento" de populações tradicionais e/ ou de territórios tradicionais.

26 Entrevista disponível em: http://www.jornalminuano.com.br/noticia/2020/08/23/comite-solicita-cancelamento-delicenca-de-mineracao-em-lavras-do-sul-apos-laudo-do-ministerio-publico. Acessado em: 28 out. 2020.

${ }^{27}$ O caso do Projeto Fosfato Três Estradas, em Lavras do Sul, está notificado como um conflito socioambiental de visibilidade internacional e está mapeado na plataforma EJAtlas: https:/www.ejatlas.org/conflict/phosphate-miningproject-in-lavras-do-sul-rio-grande-do-sul-brazil
} 
processo para que os ritos do licenciamento sejam executados conforme as normativas legais competentes.

Quadro 1 - Cronograma do processo de Licenciamento Ambiental do Projeto Fosfato Três estradas.

$\rightarrow 2011$ - (Águia) iniciou os trabalhos de pesquisa mineral no projeto.

$\rightarrow 2015$ - Os estudos ambientais para a elaboração do EIA/RIMA foram iniciados no mês de setembro.

$\rightarrow 2017$ - Estudos incompletos foram apresentados à FEPAM no mês de agosto.

$\rightarrow 2018$ - FEPAM solicitou complementações ao EIA

$\rightarrow 2018$ - Dezembro - complemento - Relatório de Atendimento ao Ofício no FEPAM/DMIN/9917/2018.

$\rightarrow$ 2018/2019 - Primeira audiência pública cancelada.

$\rightarrow 2019$ - Março - Única audiência pública realizada no mês de março em Lavras do Sul.

$\rightarrow 2019$ - Março e Abril - Abaixo-assinados pedindo audiência pública em Dom Pedrito e na comunidade de Três Estradas, em Lavras do Sul - não assistida pela FEPAM.

$\rightarrow 2019$ - Maio - Após a complementação de informações, em maio e agosto de 2019, a Licença Prévia (LP) $n^{\circ} 00355 / 2019$ para o projeto foi concedida pela FEPAM, em 15/10/2019.

$\rightarrow 2019$ - Junto com a LP, a Fepam pede condicionantes, estudos e programas ambientais.

$\rightarrow 2020$ - Maio - Laudo PGR - em 25/05/2020. Perícia do MPF. Laudo técnico no 864/2020 analisando EIA/RIMA e o complemento do "Relatório de Atendimento ao Ofício no FEPAM/DMIN/9917/2018".

$\rightarrow 2020$ - Junho - Ajustes na Fase 1 do Projeto Fosfato Três Estradas, com redimensionamento do Projeto produzido pela empresa no mês de maio. "Projeto Fosfato Três Estradas adaptações na Fase 1 município de Lavras do Sul, Rio Grande do Sul”.

$\rightarrow 2020$ - Junho - 26 de junho de 2020 - resposta da FEPAM aos ajustes socioambientais da Águia, reiterando que o aprovado na LP é o que segue vigente, mas particionando as condicionantes ambientais às demais fases do projeto.

$\rightarrow 2020$ - Agosto - Laudo PGR - em 02/07/2020. Laudo Pericial no 938/2020 - reconhece a presença de Pecuaristas Familiares entendidos como Comunidade Tradicional.

$\rightarrow 2020$ - Novembro - Laudo PGR - Laudo técnico no 1372/2020, complementar ao LT no 864/2020, em vista das recentes alterações apresentadas pela empresa na Fase 1.

$\rightarrow 2021$ - Janeiro - Águia Resources apresenta o pedido de Licença de Instalação à FEPAM

Fonte: Prates, Alt e Barcellos (2020), com atualizações.

O que é possível perceber ao longo do conjunto de eventos é que há uma aceleração nos procedimentos que inclusive impede que localidades vizinhas diretamente impactadas pelos efeitos negativos do projeto, como a cidade de Dom Pedrito, sejam informadas no processo de audiência pública, pedido reforçado pelo MPF da $3^{\text {a }}$ região.

A dissonância apontada entre uma perspectiva da democratização dos saberes, de respeitar o tempo de articulação das populações é atropelada pela tentativa de alterar processos administrativos, como o fracionamento do processo de obtenção da viabilidade ambiental do licenciamento em três fases. Questões consideradas graves, como as de segurança hídrica da região, segurança das barragens e da geração de poluentes no ar, estão sendo empurradas para serem debatidas depois. Até o momento a FEPAM está coadunando com o arranjo forjado para construção do empreendimento. 
Reforça-se que, ao realizar as alterações, a empresa busca amenizar os impactos relativos à construção de barragens nas próximas fases do projeto. Ao mesmo tempo, não consideram a combinação de passivos ambientais de outros ciclos minerários em Lavras do Sul - RS e região com a falta de rigor técnico e controle ambiental da FEPAM, órgão responsável pelos licenciamentos e a fiscalização ambiental.

Ao levar em consideração o conjunto de elementos discutidos sobre a configuração deste conflito ambiental, é perceptível as concepções divergentes sobre o que é desenvolvimento, a exemplo de territórios com grande patrimônio natural, produção agrícola e pecuária familiar, grande presença de artefatos arqueológicos e atividades turísticas. E essas concepções, interesses e projetos distintos configuram situações crescentes de conflitos ambientais a partir de situações de mobilização social, litígios judiciais no contexto do RS, em especial na região do bioma Pampa, devido à possível instalação de empreendimentos de mineração na atualidade.

\section{CONSIDERAÇÕES FINAIS}

As oposições ao avanço das fronteiras minerais para o Rio Grande do Sul configuram uma série de engendramentos para denunciar as alterações operadas pela rede que busca construir o projeto. Esse grande arranjo composto por grupos transnacionais, nacionais, estaduais e municipais estimulam a construção do projeto nos moldes modernos de desenvolvimento e progresso. Os impeditivos ambientais conquistados pelas legislações vigentes estão em processo célere de sucateamento em especial no atual governo federal. Dessa forma, a reformulação ou flexibilização dos instrumentos legislativos de regulamentação ambiental criam um ambiente propício para ingerências e irregularidades no processo do EIA - RIMA.

Essas relações de interdependência acerca da disputa de interesses sobre a instalação do Projeto Fosfato Três Estradas configuram conflitos internos nas comunidades, onde parte de seus habitantes defende a mineração e a outra denuncia os riscos sociais e ambientais a que estão sujeitos. Isto é, a geração de conflitos e a cisão interna das sociabilidades das comunidades é outra estratégia de licenciamento social utilizada pelas empresas de mineração a partir do convencimento e cooptação de alguns líderes e representantes políticos das comunidades, por meio do marketing, envolvendo a licença social para operar. Dessa forma, o conflito ambiental se capilariza entre atores locais das comunidades, obscurecendo a responsabilidade e os interesses financeiros e especulativos das empresas a partir da exploração e dos danos ambientais que serão causados. Esses processos sociais são permeados de estratégias, acordos, ressignificações de ideias e alianças políticas entre variados atores, que em geral operam negando a existência das complexidades locais. Exemplo disso é o "esquecimento" da presença de povos e comunidades tradicionais existentes na região, que é parte de um patrimônio cultural específico. 
Por fim, mas apenas iniciando outras possibilidades interpretativas, não há uma definitiva compreensão acadêmica acerca da problemática apresentada nesse trabalho. Provavelmente em 2021 ocorrerão desfechos e eventos considerados decisivos sobre a instalação do empreendimento Fosfato Três Estradas, e por isso se faz necessário refletir e pesquisar as consequências dessas disputas para o futuro. Assim, a partir deste artigo, busca-se deixar em aberto outras questões e possibilidades de pesquisa para os (as) demais pesquisadores (as) em relação aos conflitos ambientais no Brasil, a mineração e, sobretudo, sobre a expansão da exploração aos bens naturais no bioma Pampa brasileiro.

\section{REFERÊNCIAS}

ACSELRAD, H. Ambientalização das lutas sociais - o caso do movimento por justiça ambiental. São Paulo: Estudos avançados, v. 24, n. 68, p. 103-119, 2010.

ACSELRAD, H; DA SILVA, M. G. Rearticulações sociais da terra e do trabalho em áreas de grandes projetos hidrelétricos na Amazônia - o caso de Tucuruí. In: Zhouri, A. (Org.). As Tensões do lugar hidrelétricas, sujeitos e licenciamento ambiental. Belo Horizonte: EdUFMG, 2011, p. 6192.

ÁGUIA RESOURCES. Projeto Fosfato Três Estradas adaptações na fase 1, processo n ${ }^{\circ}$ 740405.67/18.8. FEPAM, 2020.

ÁGUIA RESOURCES. Relatório de Impacto Ambiental (RIMA). Projeto Fosfato três Estradas: Lavras do Sul/ RS. Golder Associates, agosto de 2017.

BONGIOLO, Everton Marques. Integração dos dados mineralógicos, isótopos estáveis (O,H) e porosidade de rochas (14 C-PMMA) no reconhecimento da evolução da alteração no sistema hidrotermal de Lavras do Sul, RS, Brasil. 2006. 188 p. Tese (Doutorado em Geociências). Instituto de Geociências, Universidade Federal do Rio Grande do Sul, Porto Alegre, 2006.

BRUCH, Alexandre Felipe; CAVALHEIRO, Sandro; GARCIA, Marcelo Tavares; MAINO, Jeferson de Mello; WINTER, Stefanie Kohn; NOVAES, Luis Eduardo Silveira da Mota. Impactos sócio-ambientais causados pela deposição de rejeitos de mineração na localidade de Minas do Camaquã, Caçapava do Sul/RS, 2006. Disponível em: http://www.ufpel.edu.br/cic/2006/arquivos/CH_00478.rtf. Acesso em: 22 out. 2010.

NEIBURG, Federico; WAIZBORT, Leopoldo (orgs.). Escritos \& ensaios. Vol. 1: Estado, processo, opinião pública. Rio de Janeiro, Jorge Zahar, 2006. 238 p.

FEPAM. Divisão de Mineração - DMIN. Parecer Técnico $n^{\circ}$ 302/2020 - Junho, 2020.

FRIZZO, Taís Cristine Ernst. Zoneamento da vegetação e sua relação com metais pesados na mina Volta Grande, Lavras do Sul, RS, ago. 2002. Porto Alegre. 137 f. Dissertação (Mestrado em Ecologia) Programa de Pós-Graduação em Ecologia. UFRGS. 2002.

GONÇALVES, R. J. A. F.; MILANEZ, B.; WANDERLEY, L. J. NEOEXTRATIVISMO LIBERAL-CONSERVADOR: a Política Mineral e a Questão Agrária no Governo Temer . OKARA: Geografia em debate, v.12, n.2, p. 348-395, 2018.

GRAZIA, Carlos Antonio; PESTANA, Maria Heloísa Degrazia. Contaminação por mercúrio antrópico em solos e sedimentos de corrente de Lavras do Sul, RS, Brasil. In: International Workshop on Medical Geology. Rio de Janeiro: CPRM, 2005. 
GUDYNAS, E. O novo extrativismo progressista na América do Sul: teses sobre um velho problema sob novas expressões. In P. Léna \& E. Pinheiro do Nascimento (Eds.), Enfrentando os limites do crescimento. Sustentabilidade, decrescimento e prosperidade. Rio de Janeiro: Garamond; IRD, 2012. (pp. 303-318).

GUDYNAS, E. Transições ao pós-extrativismo. Em Descolonizar o imaginário: debates sobre pósextrativismo e alternativas ao desenvolvimento. São Paulo, Brasil: Fundação Rosa Luxemburgo, Autonomia Literária e Elefante Editora, 2016.

HASENACK, Heinrich. Determinantes biofísicos e geopoliticos do uso da terra no estado do Rio Grande do Sul. 2017. Porto Alegre. Tese de Doutorado. 82 f. Programa de Pós-Graduação em Agronegócios. UFRGS.2017.

IBGE. Instituto Brasileiro de Geografia e Estatística/Coordenação de Recursos Naturais e Estudos Ambientais, Coordenação de Contas Nacionais. Contas de ecossistemas: o uso da terra nos biomas brasileiros: 2000-2018. 2020. Disponível em: https://biblioteca.ibge.gov.br/visualizacao/livros/liv101753.pdf. Acessado 12 dez 2020.

LAUDO PERICIAL No 938/2020/SPPEA- MINISTÉRIO PÚBLICO FEDERAL- Secretaria de Perícia, pesquisa e análise. PROCESSO 1.29.001.000136/2017-92.

MPF. MINISTÉRIO PÚBLICO FEDERAL. Inquérito Civil - - nº 1.29.001.000136/2017-92. 2020.

NESKE, Márcio Zamboni. Colonialidade e desenvolvimento: a ressignificação do lugar em 'zonas marginalizadas' no sul do Rio Grande do Sul. Rio Grande do Sul, 2014. Tese (Doutorado em Programa de Pós-Graduação em Desenvolvimento Rural) - Universidade Federal do Rio Grande do Sul, 2014.

OLIVERIA R., LOSEKANN C. (2015) «Decidindo como decidir: os indígenas Munduruku e a participação política no Brasil», Open Democracy / ISA RC-47: Open Movements, 2 June. Disponível em: https://opendemocracy.net/cristiana-losekann-rodrigo-oliveira/decidindo-comodecidir-os-indígenas-munduruku-e-participação-pol . Acessado em: 20 nov 2020.

PRATES, Camila; ALT, Júlio; BARCELLOS, Sérgio. Parecer CEDH-RS $N^{o}$ 01/2020 sobre a atuação estatal a partir de empreendimento minerário em Três Estradas, Lavras do Sul, RS. Relatórios. Conselho Estadual de Direitos Humanos (CEDH) - RS. 2020. Disponível em: https://drive.google.com/file/d/1dhC3GgkXmmbdnTv7UOaxv3vlZ30Pc93O/view . Acessado em: 03 jan 2021.

RIETH, Flávia Maria Sila; CARLE, Cláudio; OLIVEIRA, Cícero; LIMA, Daniel Vaz; NUNES, Juliane dos Santos.; BARBOSA, Luciene . Inventário nacional de referências culturais: lida campeira nos campos dobrados do Alto Camaquã: Os Saberes e Modos de Fazer Pecuários no Município de Lavras do Sul/RS, 2020. Disponível em: https://wp.ufpel.edu.br/lidacampeira/. Acessado em: 03 jan 2021.

SEMA. Secretaria do Ambiente e Desenvolvimento Sustentável. A Bacia Hidrográfica do Rio Santa Maria. Disponível em: http://www.sema.rs.gov.br/bacia-hidrografica-do-rio-santa-maria. Acesso em: jun. 2017.

STENGERS, Isabelle. A proposição cosmopolítica. Revista do Instituto de Estudos Brasileiros, Brasil, n. 69, p. 442-464, abr. 2018.

SZABLOWSKI, D. Transnational law and local struggles: mining, communities and the World Bank. Portlhand: Hart Publishing, 2007.

THOMSON, I. Pela política da boa vizinhança. Ideia Sustentável, São Paulo, 31 jan. 2014. Entrevista concedida a Poliana Abreu. Disponível em: https://ideiasustentavel.com.br/pela-politicada-boa-vizinhanca/. Acesso em: 30 nov. 2014. 
ZHOURI, Andréa, LASCHEFSKI, Klemens. Desenvolvimento e conflitos ambientais um novo campo de investigação. IN: ZHOURI, Andréa, LASCHEFSKI, Klemens (orgs). Desenvolvimento e Conflitos Ambientais. Belo Horizonte: Editora UFMG, 2010. 